\title{
Hypoplastic myelodysplastic syndrome and acquired aplastic anemia: Immune-mediated bone marrow failure syndromes (Review)
}

\author{
HANA VOTAVOVA and MONIKA BELICKOVA \\ Department of Genomics, Institute of Hematology and Blood Transfusion, Prague 128 00, Czech Republic
}

Received October 19, 2021; Accepted December 1, 2021

DOI: $10.3892 /$ ijo.2021.5297

\begin{abstract}
Hypoplastic myelodysplastic syndrome (hMDS) and aplastic anemia (AA) are rare hematopoietic disorders characterized by pancytopenia with hypoplastic bone marrow (BM). hMDS and idiopathic AA share overlapping clinicopathological features, making a diagnosis very difficult. The differential diagnosis is mainly based on the presence of dysgranulopoiesis, dysmegakaryocytopoiesis, an increased percentage of blasts, and abnormal karyotype, all favouring the diagnosis of hMDS. An accurate diagnosis has important clinical implications, as the prognosis and treatment can be quite different for these diseases. Patients with hMDS have a greater risk of neoplastic progression, a shorter survival time and a lower response to immunosuppressive therapy compared with patients with AA. There is compelling evidence that these distinct clinical entities share a common pathophysiology based on the damage of hematopoietic stem and progenitor cells (HSPCs) by cytotoxic T cells. Expanded T cells overproduce proinflammatory cytokines (interferon- $\gamma$ and tumor necrosis factor- $\alpha$ ), resulting in decreased proliferation and increased apoptosis of HSPCs. The antigens that trigger this abnormal immune response are not known, but potential candidates have been suggested, including Wilms tumor protein 1 and human leukocyte antigen class I molecules. Our understanding of the molecular pathogenesis of these BM failure syndromes has been improved by next-generation sequencing, which has enabled the identification of a large spectrum of mutations. It has also brought new challenges, such as the interpretation of variants of uncertain significance and clonal hematopoiesis of indeterminate potential. The present review discusses the main clinicopathological differences between hMDS and acquired
\end{abstract}

Correspondence to: Dr Monika Belickova, Department of Genomics, Institute of Hematology and Blood Transfusion, U nemocnice 2094/1, Prague 128 00, Czech Republic

E-mail: monika.belickova@uhkt.cz

Key words: hypoplastic myelodysplastic syndrome, acquired aplastic anemia, mutational landscape, dysregulated non-coding RNAs, immunopathogenesis
AA, focuses on the molecular background and highlights the importance of molecular testing.

\section{Contents}

1. Introduction

2. Mutational landscape

3. Dysregulation of non-coding RNA (ncRNA)

4. Pathophysiology

5. Genetic and molecular basis of an aberrant immune response 6. Conclusions

\section{Introduction}

Myelodysplastic syndrome (MDS) is a clonal hematopoietic stem cell (HSC) disorder characterized by ineffective erythropoiesis, dysplasia involving one or more cell lineages, peripheral cytopenia and an increased risk of transformation to acute myeloid leukemia (AML). In developed countries, the incidence of MDS increases progressively with age and the annual incidence of the disease is estimated to be 4 cases per 100,000 people, rising to 30 cases per 100,000 people in those $>70$ years old $(1,2)$. Men have a higher incidence rate than women (2). Although the bone marrow (BM) of most patients with MDS is normo- or hypercellular (NH-MDS), $10-20 \%$ of patients with MDS have hypocellular BM (cellularity $<20-30 \%$ in the BM trephine biopsy) $(2,3)$. This subset is referred to as hypoplastic MDS (hMDS) in the World Health Organization (WHO) classification of myeloid neoplasms (4), but it is not currently considered a separate entity. Most cases of hMDS are classified as MDS with single- and multiple-lineage dysplasia in the WHO classification system. Hypocellular BM is predominantly found in low-risk MDS, but can also be observed in high-risk MDS $(5,6)$.

hMDS shares some clinical manifestations with NH-MDS, such as cytopenia, BM dyspoiesis, clonal chromosomal changes and the possibility of transformation to AML. By contrast, it shows distinctive features associated with decreased BM cellularity, including more profound neutropenia and thrombocytopenia, and a lower percentage of blasts (7). Furthermore, patients with hMDS have less frequent abnormal karyotypes, a higher response rate to immunosuppressive therapy (IST) 
and a more favourable prognosis compared with patients with NH-MDS. Notably, patients with hMDS tend to be younger (hMDS is the most common MDS type in pediatric patients) (7). Since marrow cellularity decreases with age, age-adjusted criteria of hypocellularity have been proposed (e.g., $<30 \%$ cellularity in patients $\leq 70$ years and $<20 \%$ cellularity in patients $>70$ years) (8).

hMDS is initially treated as low-risk MDS, but treatment may be tailored according to the degree of similarity to aplastic anemia (AA) or MDS. AA-like treatment is based on IST with anti-thymocyte globulin (ATG) and cyclosporine A, which suppresses the activity of aberrant $\mathrm{T}$ cells and helps with BM recovery. Approximately $50 \%$ of low-risk MDS patients show an objective IST response, which is associated with hypocellular BM and increased rates of transfusion independence (9). A high overall response rate (ORR) (73\%) was reported in a study that focused only on hMDS treated with IST (10). Supportive care in low-risk MDS includes red blood cell (RBC) transfusions, antibiotics and erythropoietin for stimulation of RBC production. Hypomethylating agents (HMAs), such as azacytidine or decitabine, have recently been administered to high-risk patients, but these agents are effective in only $\sim 50 \%$ of MDS patients in the short term, and a number of patients develop drug resistance and progress to AML (11). Targeted therapy using BCL2 and immune checkpoint inhibitors is being tested in combination with HMAs. HMA therapy may be a reasonable option for patients with hMDS who have high-risk cytogenetics and unfavourable somatic mutations (12). HSC transplantation (HSCT) is the only curative option for patients with MDS; however, numerous patients are not eligible for HSCT due to comorbidities usually associated with older age (13). Recently, Zhou et al (14) evaluated the outcomes of exclusively hMDS patients after allogenic HSCT; the patients had favourable survival rate, and none of them relapsed within a follow-up period of $\sim 3$ years.

$\mathrm{AA}$ is a rare BM failure (BMF) characterized by hypoplastic or aplastic BM, a paucity of hematopoietic stem and progenitor cells (HSPCs), and pancytopenia of the peripheral blood. In North America and Europe, the incidence of AA is 2-3 cases per million per year, but may be three-fold higher in Asian populations (15). AA is a disease that affects the young, typically within the first three decades of life, with a median age of onset of $\sim 20$ years old. The second peak occurs at $\sim 60$ years old (16). In some cases, inherited conditions, such as Fanconi anemia, Shwachman-Diamond syndrome and dyskeratosis congenital, can damage stem cells and lead to AA (17). Acquired AA is more frequent, and it may be caused by toxic chemicals, radiation or idiosyncratic reactions to medications or infections (18). However, in $>50 \%$ of cases, there is no identifiable cause and the condition is then referred to as idiopathic AA (iAA). In iAA, a dysregulated immune system destroys HSCs either directly by activation of apoptosis or indirectly by overproduction of inflammatory cytokines. Evolution to MDS or AML occurs in up to $20 \%$ of AA patients, especially in those with an incomplete response to IST (19).

Patients with mild or moderate AA generally do not require immediate treatment, but patients with severe AA should be treated as soon as possible after diagnosis. A crucial part of patient care is supportive treatment that is focused on the prevention of infections (antibiotics) and bleeding
(RBC/platelet/granulocyte transfusions). Immunosuppression with ATG and cyclosporine A is frontline treatment in older patients with AA and in patients for who matched BM donors are not available. A total of $60-70 \%$ of patients with AA show long-term durable ORR after IST (20) and may show higher response rates for IST compared with those with hMDS (21). Paroxysmal nocturnal hemoglobinuria (PNH) clones have recently been shown to be a good predictor of IST response in AA as well as MDS (22). Some patients with AA treated with IST develop clonal hematopoiesis or somatic mutations and progress to MDS or AML (23). Corticosteroids, such as methylprednisolone, are often used with immunosuppressants. Furthermore, AA therapy includes BM stimulants, such as granulocyte monocyte colony-stimulating factor or platelet growth factor (eltrombopag). Generally, HSCT is reserved for young patients and those with severe AA $(<50$ years old) who are more likely to have potentially fatal complications. Recently, Zhu et al (24) performed a meta-analysis of studies on HSCT and IST in AA, and observed longer survival times in patients after first-line allo-HSCT compared with times in those treated with first-line IST (24). However, the potential risks and benefits of HSCT should be considered for each individual patient.

Patients with hMDS and AA share overlapping clinical and pathological features; thus, distinguishing between these patients can be very difficult. An accurate diagnosis has important clinical implications, as prognosis and treatment can be quite different for these diseases. The differential diagnosis is mainly based on the presence of dysgranulopoiesis, dysmegakaryocytopoiesis, any ring sideroblasts, an increased percentage of blasts and abnormal karyotype, all favouring the diagnosis of hMDS (7). hMDS has a greater risk of neoplastic progression and a shorter survival time compared with AA (Table I) (3,7). Clonal cytogenetic abnormalities are considered typical of MDS, but they are usually found in only half of all MDS patients, and cytogenetic analyses may be less reliable when the BM is hypocellular (3). An increased percentage of $\mathrm{CD} 34^{+}$cells and a tendency of positive cells to form aggregates may be useful in distinguishing hypoplastic myeloid neoplasms (hMDS and hypocellular AML) from AA (25). Furthermore, elevated levels of serum thrombopoietin have recently been reported in AA compared with those in hMDS and may also help to discriminate between these disorders (26).

\section{Mutational landscape}

$M D S$. MDS develops through a multistep process encompassing an initial deleterious genetic event within a HSC and successive genetic abnormalities, leading to clonal expansion and malignant transformation (27). In recent years, the understanding of the molecular pathogenesis of MDS has been markedly improved by next-generation sequencing (NGS), which has enabled the identification of a large spectrum of new mutations across all MDS subtypes. There are $>40$ significantly mutated genes in MDS, and these mutations account for nearly $90 \%$ of patients with MDS (28). Functionally, the mutations are grouped into several categories based on their prevalence: RNA splicing factors [splicing factor 3B subunit 1 (SF3B1), serine and arginine rich splicing factor 2 (SRSF2), zinc finger $\mathrm{CCCH}$-type, RNA binding motif and serine/arginine rich 2 (ZRSR2) and U2 


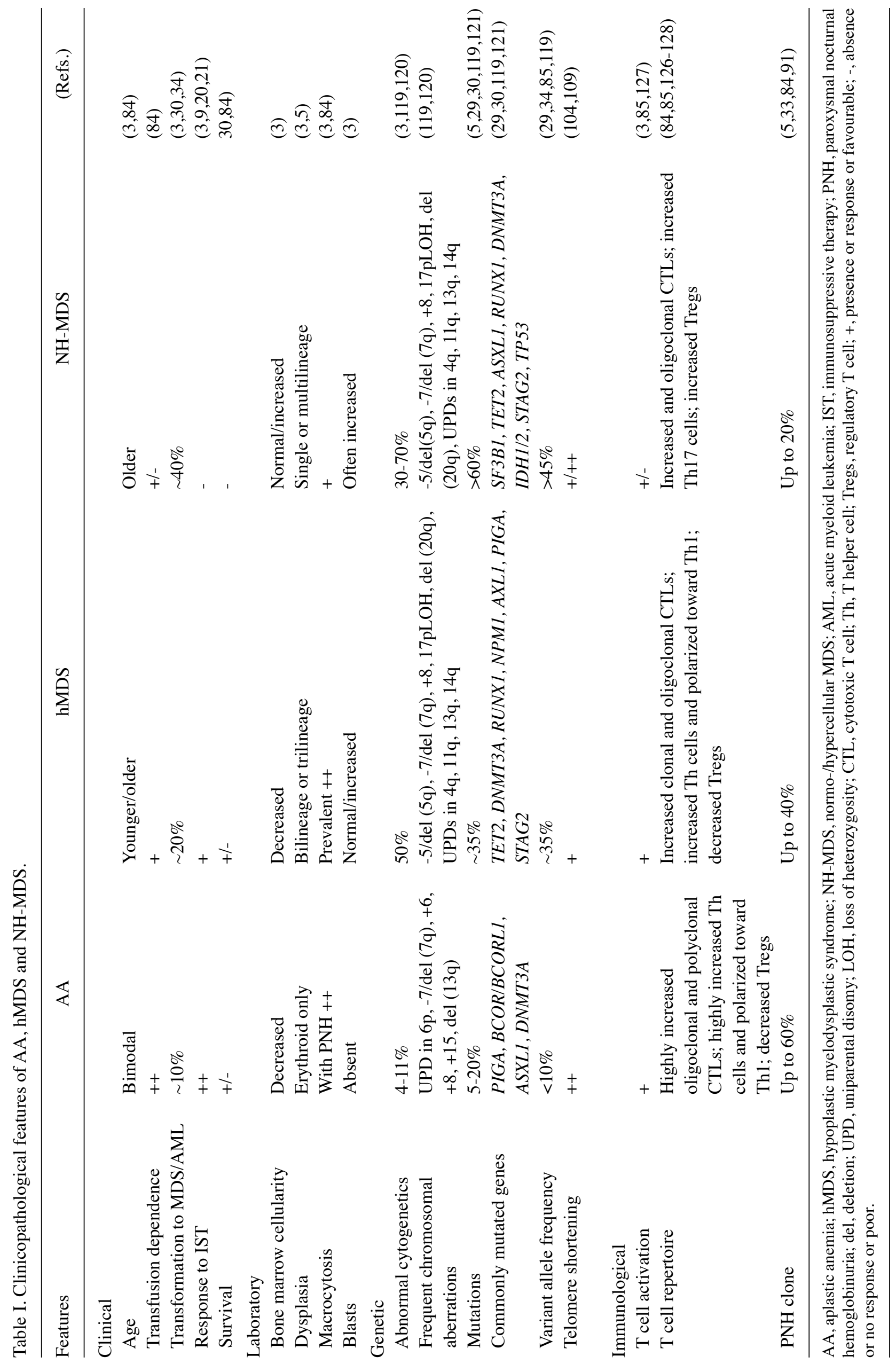


small nuclear RNA auxiliary factor $1 / 2(U 2 A F 1 / 2)]$, epigenetic regulators [Tet methylcytosine dioxygenase 2 (TET2), DNA methyltransferase $3 \alpha(D N M T 3 A)$ and isocitrate dehydrogenase (NADP(+)) $1 / 2(I D H 1 / 2)]$, components of the cohesion complex (stromal antigen 2, CCCTC-binding factor, structural maintenance of chromosomes 1A and RAD21 cohesin complex component), chromatin modifiers [ASXL transcriptional regulator $1(A S X L 1)$ and enhancer of zeste 2 polycomb repressive complex 2 subunit $(E Z H 2)$ ], transcription factors [tumor protein p53 (TP53), RUNX family transcription factor 1 $(R U N X I)$, ETS variant transcription factor 1 (ETVI) and GATA binding protein 2 (GATA2)], signal transduction molecules [Fms related receptor tyrosine kinase 3 (FLT3), Janus kinase 2 (JAK2), MPL proto-oncogene thrombopoietin receptor (MPL), GNAS complex locus and KIT proto-oncogene receptor tyrosine kinase], RAS pathway [KRAS proto-oncogene GTPase, NRAS proto-oncogene GTPase (NRAS), Cbl proto-oncogene, neurofibromin 1 and protein tyrosine phosphatase non-receptor type 11 (PTPN11)] and DNA repair [ATM serine/threonine kinase, BRCA1/BRCA2-containing complex subunit 3, DNA cross-link repair 1C and FA complementation group L]. Mutations in RNA splicing and DNA methylation genes seem to occur early and are considered founder mutations in $>50 \%$ of patients with MDS (28). Mutations provide a wide range of prognostic information, from benign to malignant and from good to poor overall survival (OS) time. For example, TP53, $E Z H 2$, ETS variant transcription factor 6 (ETV6), RUNX1, $A S X L 1$ and $S R S F 2$ mutations predict shorter survival time. The $S F 3 B 1$ mutation is strongly associated with ring sideroblasts and thus has been included as a diagnostic criterion in MDS with ring sideroblasts (4).

There are several reports concerning differences in the mutational landscapes between hMDS and NH-MDS (Fig. 1). Nazha et al (29) compared the mutational profiles of 62 genes between patients with hMDS and NH-MDS. Patients with hMDS acquired fewer somatic mutations and had smaller driver clones compared with patients with NH-MDS. Splicing somatic mutations were determined predominantly in patients with NH-MDS, as driver clones were found exclusively in these patients. The study hypothesized that the immune system in patients with hMDS may suppress the driver clone by inhibiting its growth and genetic evolution, thus limiting the acquisition of downstream somatic lesions. Notably, some driver clones, such as SF3B1,SRSF2,TET2, ASXL1 and BCL-6 coreceptor (BCOR), may overcome this inhibitory effect (29). Yao et al (30) detected at least one gene mutation (17 genes) in $35 \%$ of patients with hMDS, and the most common mutation was an SF3B1 mutation. Patients with hMDS exhibited significantly lower incidence rates of RUNX1, ASXL1, DNMT3A, EZH2 and TP53 mutations, and a lower number of mutations per subject compared with patients with NH-MDS; however, the number was significantly higher in comparison with the number in patients with AA. Schwartz et al (31) used a whole exome sequencing approach to describe somatic and germline changes in pediatric MDS and found prevalent Ras/MAPK pathway mutations compared with that in adult MDS. Huang et al (6) did not find any difference in the incidence of $R A S$, acute myeloid leukemia 1 protein, JAK2, PTPN11 or FLT3/internal tandem duplication mutations between hMDS and non-hMDS. Bono et al (5) reported mutational data from a 24-gene panel on a large cohort of hMDS patients ( $n=93)$ and detected one or more somatic mutations in $38 \%$ of patients with hMDS. In comparison to non-hMDS patients $(n=239)$, the patients with hMDS had a lower number of mutations per subject, but this number was significantly higher than that found in the patients with AA. The prevalence of splicing mutations (SF3B1 and SRSF2) and co-mutation patterns of TET2, DNMT3A and ASXL1 was lower in hMDS compared with that in non-hMDS. The integration of mutational data into a scoring formula enabled the separation hMDS patients with myeloid neoplasm-like profiles from those with non-malignant profiles. It was suggested that hMDS more likely represents a mixture of entities along a spectrum rather than a homogeneous in-between category (5).

Taken together, these results suggest that the mutational profile of hMDS overlaps with the profile of NH-MDS, except for the lower incidence of mutations in splicing factors and in $A S X L 1$ and $I D H 1 / 2$ genes. Patients with hMDS have fewer somatic mutations, and overall, smaller driver clones.

$A A$. In AA, the most frequently mutated genes are phosphatidylinositol glycan anchor biosynthesis class A (PIGA), BCOR/BCOR-like 1 (BCORL1), DNMT3A and ASXL1, suggesting mechanisms of clonal selection. Mutations in PIGA and $B C O R / B C O R L 1$ are more specific to AA, while $D N M T 3 A$ and ASXL1 mutations are also found in MDS (Fig. 1). PIGA somatic mutations are found in up to $40 \%$ of patients with AA $(16,32)$. PNH clones are detected in a higher proportion of patients with AA (up to $60 \%$ ) and have been shown to escape T cell-mediated destruction. Blood cells with PIGA mutations are likely less immunogenic and thus may acquire a survival advantage (33). Somatic mutations in JAK2/JAK3, RUNX1, TP53, TET2, and CUB and sushi multiple domains 1 genes are less common in AA, and SRSF2, U2AF1, MPL and Erb-B2 receptor tyrosine kinase 2 mutations are rare $(<3 \%$ of acquired AA cases) (34). Detected somatic mutations in AA have mostly variant allelic frequencies of $<10 \%(23,34)$. Patients with AA and PIGA, BCOR or BCORL1 mutations show a better response to IST, as well as improved progression-free survival (PFS) and OS rates, while DNMT3A, ASXL1, JAK2/JAK3 or $R U N X 1$ mutations are associated with a worse IST response and survival rate. Notably, mutations in DNMT3A or ASXL1 increase the risk of developing MDS from AA $(23,34,35)$. Keel et al (36) detected pathological mutations in MPL and TP53 genes in young patients with AA and MDS.

A high incidence of somatic mutations in MDS suggests that mutational profiling of myelodysplasia-related genes may help to distinguish AA from hMDS and may identify patients who are at risk for progression. Kulasekararaj et al (23) used targeted high-throughput DNA sequencing to determine somatic mutations in patients with acquired AA. Somatic mutations (ASXL1, DNMT3A, BCOR) were detected in $19 \%$ of patients with AA who had a longer disease duration and a higher risk of MDS transformation than those without mutations. Notably, the detection of ASXL1, DNMTA, BCOR and TET2 mutations in the AA cohort coupled with published expression data provides a role for the potential association and cooperation between mutations in epigenetic regulators and immune-mediated BMF. Similarly, Huang et al (37) focused on a limited number of genes and found mutations 

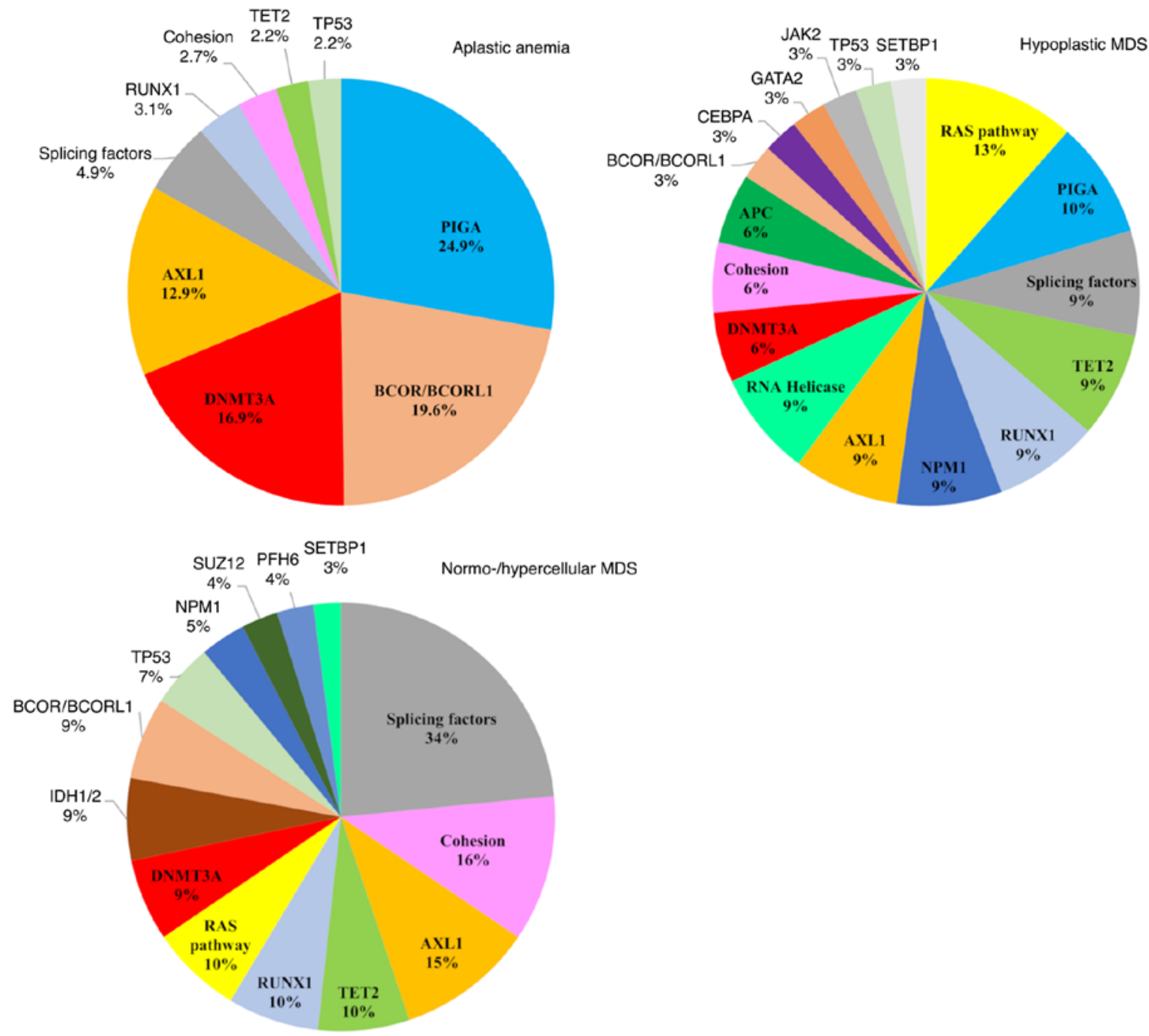

Figure 1. Relative frequency of the most common mutations in AA, hMDS and NH-MDS. Frequency of mutations in AA, hMDS and NH-MDS according to three comprehensive studies that focused on comparisons of these bone marrow failure syndromes $(29,119,121)$. Only mutations with a frequency $>2 \%$ are shown. AA, aplastic anemia; hMDS, hypoplastic myelodysplastic syndrome; NH-MDS, normo- or hypercellular MDS.

in epigenetic regulator genes, including TET2 and ASXL1, in $17.4 \%$ of patients with AA. By contrast, Heuser et al (38) identified somatic mutations in only $5.3 \%$ of patients with AA and suggested that mutations in myeloid malignancy-related genes are rare in this disease.

\section{Dysregulation of non-coding RNA (ncRNA)}

MicroRNAs. In the last two decades, it has become increasingly evident that ncRNAs are important regulators of biological processes, including blood cell differentiation and immune response. There are several categories of ncRNAs, such as microRNAs (miRNAs), Piwi-interacting RNAs, small nucleolar RNAs and long ncRNAs (lncRNAs) (39). miRNAs are the most prolific class of ncRNAs and have been shown to play a role in the pathogenesis of MDS (40). Comprehensive data are available on expression miRNA profiles associated with MDS subtypes, disease stages and treatment response, as well as on dysregulation of specific miRNAs and their role in pathogenesis (Table II). As MDS originates in HSCs, a number of studies have been performed on $\mathrm{CD} 34^{+}$cells.
Abundantly expressed miRNAs in $\mathrm{CD}_{3} 4^{+}$cells of patients with MDS include, but are not limited to, let-7b, miR-10a, $m i R-25$, the $m i R-26$ family, $m i R-128 a, m i R-146, m i R-155$, $m i R-181 a, m i R-222$ and $m i R-223$ (41). To date, no study has focused on the differential expression of miRNAs between hMDS and NH-MDS. In general, low-risk patients show distinctive expression profiles compared with high-risk patients $(42,43)$. Sokol et al (43) defined a unique signature of 10 miRNAs ( $m i R-181 a / b / c / d, m i R-221, m i R-376 b, m i R-125 b$, $m i R-155, m i R-130 a$ and $m i R-486-5 p$ ) that accurately differentiated low-risk patients from high-risk patients. Notably, the 6-miRNA signature may distinguish RA/refractory cytopenias with multilineage dysplasia (RCMD) patients with a normal karyotype from those with trisomy 8, who usually show a good response to IST.

A cluster of 13 miRNAs, including miR143/miR-145, has been mapped in the deletion region del5q31-5q35 (44); these miRNAs are downregulated in a variety of human cancer types, such as colorectal and gastric cancer $(45,46)$. Haploinsufficiency of these miRNAs and miR-146a (adjacent to the commonly deleted region) contributes to the 5q-syndrome 


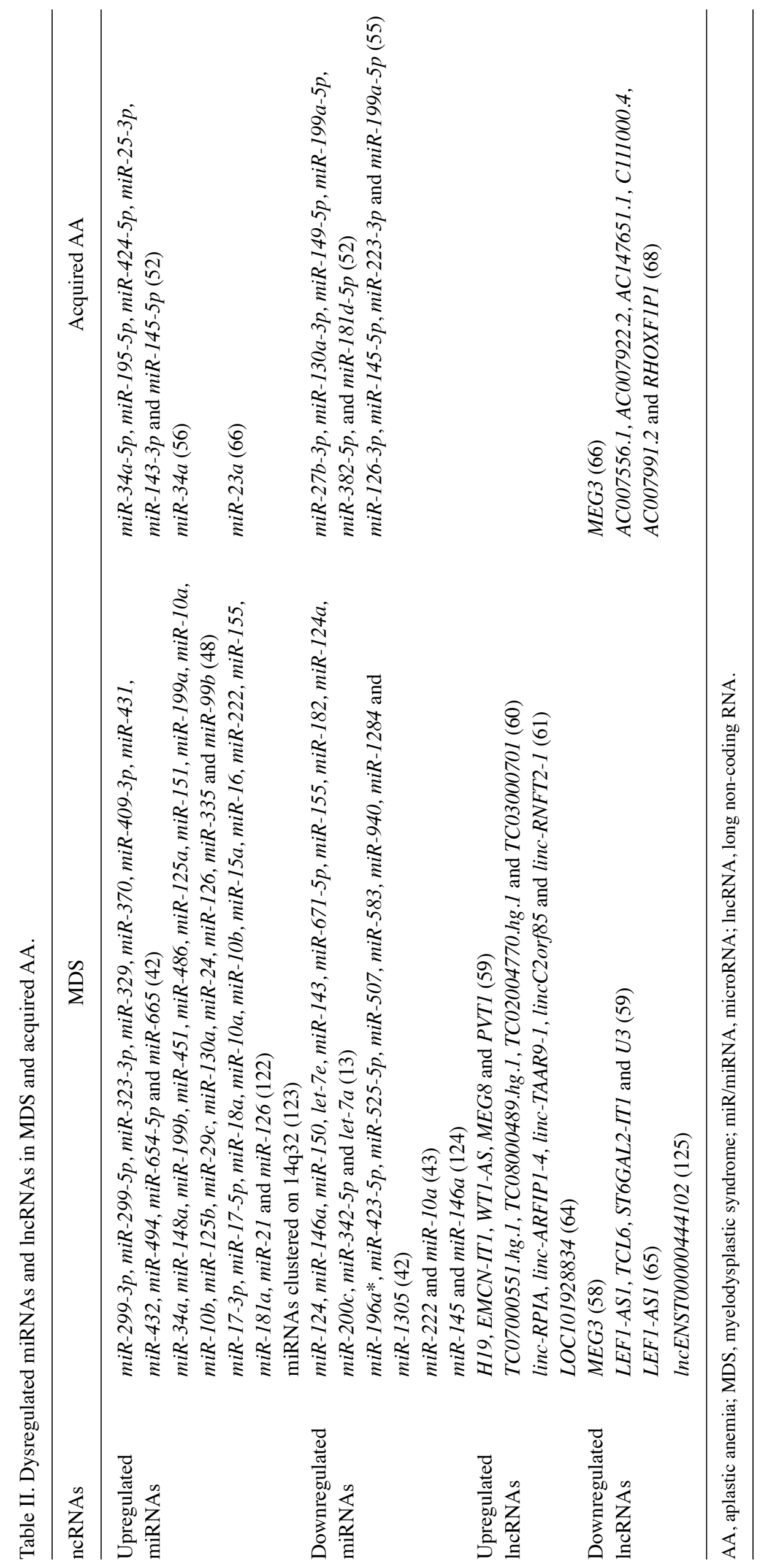


phenotype $(47,48)$. Furthermore, $m i R-145$ and $m i R-146 a$ are implicated in the dysregulation of innate immune signaling in MDS HSPCs (49). miR-146a is a negative regulator of immune cell activation; it represses two targets, tumor necrosis factor (TNF) receptor-associated factor 6 (TRAF6) and interleukin 1 receptor-associated kinase, which are signaling transducers upstream of nuclear factor $\kappa \mathrm{B}(\mathrm{NF}-\kappa \mathrm{B})(40)$. NF- $\kappa \mathrm{B}$ activation is regulated by $m i R-125 a$, which also plays a role in the regulation of innate immunity pathways and erythroid differentiation in $\operatorname{MDS}(50)$.

Compared with hMDS, acquired AA has more available miRNA data (Table II). Srivastava et al (51) recently found deregulated expression of $m i R-126, m i R-145, m i R-155$, $m i R-146$ and $m i R-150$ in AA, and determined their target genes, phosphoinositide-3-kinase regulatory subunit 2 (PIK3R2), MYC proto-oncogene (MYC), suppressor of cytokine signaling $1, T R A F 6$ and MYB proto-oncogene, respectively. In other recent study, Lu et al (52) integrated multiple expression profiles of miRNAs and mRNAs of BM $\mathrm{T}$ cells from patients with acquired AA and showed that miR-34a-5p, miR-195-5p and miR-424-5p may modulate T-cell differentiation and plasticity by targeting histone gene expression and histone modification. A similar approach was used in the study by Adhikari and Mandal (53), which identified significant upregulation of $m i R-1202$ in patients with AA compared with controls, and in which its putative targets, rap guanine nucleotide exchange factor 5 and mannosidase endo- $\alpha$, were predicted. In the plasma of patients with acquired AA, Hosokawa et al (54) identified deregulation of $m i R-150-5 p, m i R-146 b-5 p$ and $m i R-1$, which target immune pathways related to Toll-like receptors and TNF- $\alpha$. Notably, the miRNA expression was restored to normal after successful IST. In particular, $m i R-150-5 p$ showed a correlation with IST response, suggesting that it may serve as a biomarker for therapeutic monitoring (54). The same group analyzed miRNA levels in $\mathrm{CD}^{+}$and $\mathrm{CD}^{+} \mathrm{T}$ cells from patients with AA and detected downregulation of $m i R-126-3 p$ and $m i R-223-3 p$ in $\mathrm{CD}^{+} \mathrm{T}$ effector memory cells, and of $m i R-126-3 p, m i R-145-5 p$ and $m i R-223-3 p$ in $\mathrm{CD}^{+} \mathrm{T}$ effector memory and terminal effector cells. The expression levels of $m i R-126-3 p, m i R-145-5 p$ and $m i R-223-3 p$ became normal after successful IST. MYC and PIK3R2 genes were shown to be targets of $m i R-145-5 p$ and $m i R-126-3 p$, respectively (55). Sun et al (56) demonstrated that overexpression of miR-34a and downregulation of its target gene, diacylglycerol kinase $\zeta$, enhanced T-cell activation in acquired AA. Giudice et al (57) analyzed exosomal miRNAs in severe AA and MDS, and found distinctive signatures between these BMF disorders. In patients with AA, $m i R-126-5 p$ showed a negative correlation with IST response, and patients with high miRNA levels at diagnosis had the shortest PFS time compared with patients with lower or normal levels. Furthermore, $m i R-4651$ was exclusively present in severe AA responders to IST (57).

lncRNAs. IncRNAs represent another important class of ncRNAs whose role in hematopoietic disorders is being explored. Studies on lncRNAs in MDS display heterogeneity in experimental design (size of patient cohort, MDS subtypes, technologies used and analytical approaches), and thus far, no study has focused only on hMDS. The very first study by Benetatos et al (58) revealed hypermethylation of the maternally expressed 3 (MEG3) gene promoter in $34.9 \%$ of patients with MDS, which may confer a worse overall prognosis. Next, genome-wide studies defined the gene expression profiles of lncRNAs in various specific groups of patients with MDS, such as those with primary MDS $(59,60)$, refractory anemia (RA) with excess blasts type 2 (RAEB-2) MDS (61), de novo MDS and MDS evolved from AA (62). Recently, Szikszai et al (59) analyzed lncRNA expression across all MDS subtypes and evaluated them in relation to disease subtypes, cytogenetic and mutational aberrations, and risk of progression. Comparative analysis between low- and high-risk patients determined 16 deregulated lncRNAs [e.g., downregulated RP11-897M7.1 and long intergenic non-protein coding RNA 539, and upregulated $\mathrm{T}$ cell leukemia/lymphoma 6 , long intergenic non-protein coding RNA 1013, LEF1 antisense RNA 1 (LEF1-AS1) and $C T C-436 K 13.2$ in low-risk patients] (59). Yao et al (60) attempted to use IncRNA expression for the risk stratification of patients with MDS and integrated four lncRNAs (TC07000551.hg.1, TC08000489.hg.1, TC02004770.hg.1 and TC03000701.hg.1) whose expression levels were associated with OS into a risk-scoring system. Higher lncRNA scores were associated with high-risk MDS, complex karyotype, and RUNX1, ASXL1, TP53, SRSF2 and ZRSR2 mutations. In relation to the skewed $\mathrm{T}$ cell repertoire in MDS, pathway analysis of differentially expressed genes between patients with the highest and lowest lncRNA risk scores determined $\mathrm{T}$ cell-related pathways [e.g., cytotoxic T-lymphocyte-associated protein 4 signaling in cytotoxic $\mathrm{T}$ lymphocytes and CD28 signaling in T helper (Th) cells] to be the most significant (60). Hung et al (63) recently identified an association between higher KIAA0125 expression (BM mononuclear cells) and high-risk MDS, ASXL1 and NRAS mutations, and poorer OS and leukemia-free survival. A recent study by $\mathrm{Li}$ et al (64) reported an association between a higher expression level of LOC101928834 and a higher white blood cell count, a higher blast percentage, RAEB subtype and a shorter OS time in MDS. By contrast, LEF1-AS1 expression has been shown to be significantly downregulated in patients with MDS compared with that in healthy controls (65).

There are limited data on lncRNAs in AA. Recently, Wang et al (66) demonstrated decreased expression of $M E G 3$ in $\mathrm{CD}^{+} \mathrm{T}$ cells derived from patients with AA. MEG3 can act as an miRNA sponge that sequesters $m i R$-23a and induces $\mathrm{T}$ cell immunoreceptor with Ig and ITIM domains expression in $\mathrm{CD} 4^{+} \mathrm{T}$ cells, leading to the expansion of Th17 and Th1 cells and increased serum TNF- $\alpha$ and interferon- $\gamma$ (IFN- $\gamma$ ) levels. Jiang et al (67) reported that fibroblast growth factor 1 promoted the proliferation of BM mesenchymal stem cells from patients with AA by acetylation of IncRNA in the testis development related 1 gene promoter. Lu et al (68) recently analyzed differentially expressed lncRNAs and mRNAs between children with acquired AA and healthy controls. The study defined immune- or hematopoietic-related 1 c RNA/mRNA pairs [AC007556.1/dehydrogenase/reductase 9, AC007922.2/histamine receptor $\mathrm{H} 4, A C 147651.1 /$ platelet derived growth factor subunit A, $A C 111000.4 /$ growth factor independent 1B transcriptional repressor, AC007991.2/indoleamine 2,3-dioxygenase 1 


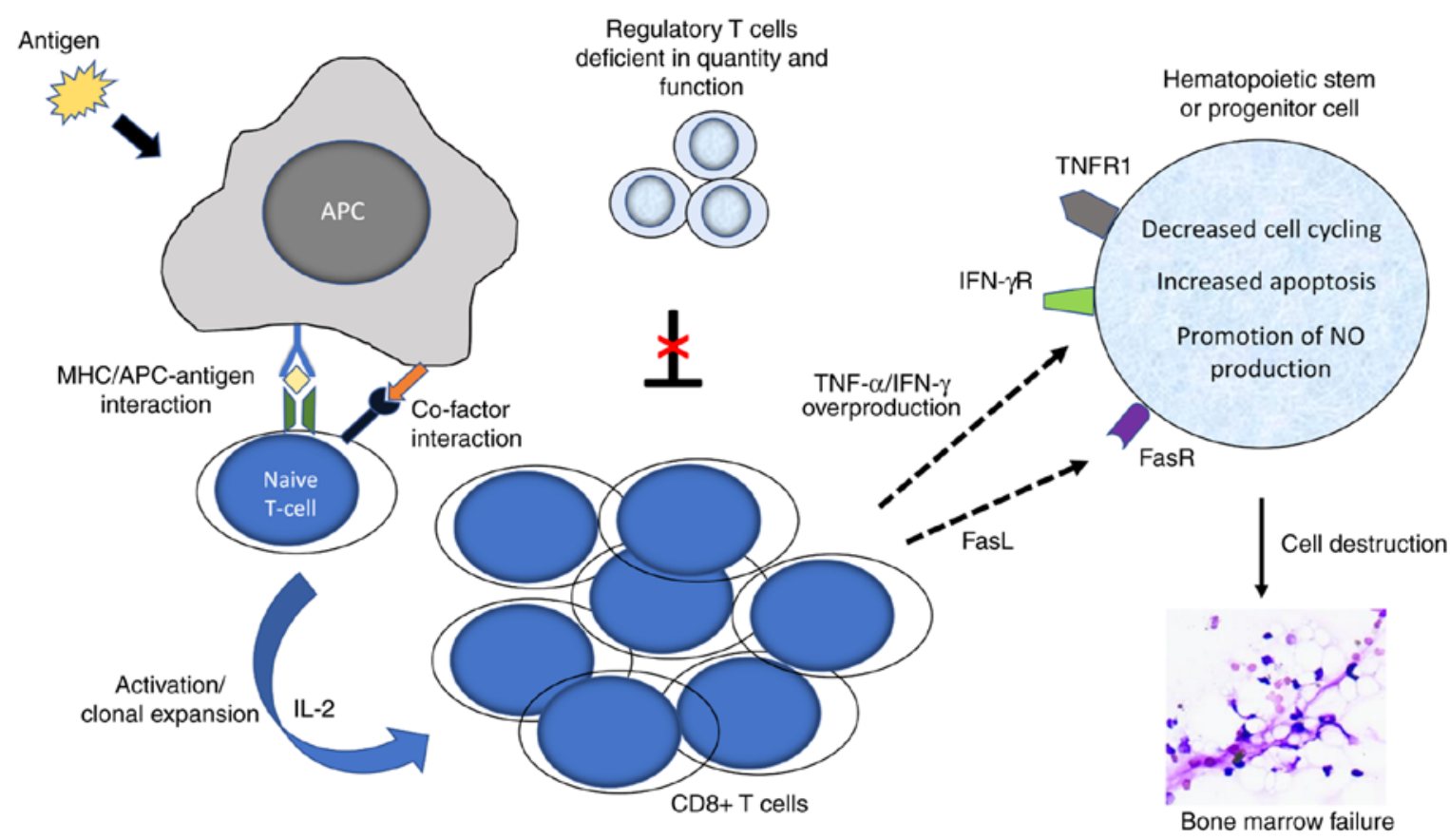

Figure 2. Proposed mechanism of hematopoietic stem cell destruction in acquired aplastic anemia. An unknown antigen that is presented by antigen-presenting cells triggers the activation of T cells that release IL-2. This results in clonal expansion of T cells overproducing proinflammatory cytokines. IFN- $\gamma$ and TNF- $\alpha$ decrease cell cycling, increase apoptosis of HSPCs and promote the production of nitric oxide, which is toxic to other HSPCs. Regulatory T cells exhibit a decreased quantity and ability to suppress the proliferation of autologous T cells. Together, these events lead to HSPC damage and bone marrow failure. Adapted from (16). HSPC, hematopoietic stem or progenitor cell; APC, antigen-presenting cell; IL, interleukin; NO, nitric oxide; MHC, major histocompatibility complex; TNF- $\alpha$, tumor necrosis factor $\alpha$; IFN- $\gamma$, interferon $\gamma$; FasR, Fas receptor; FasL, Fas ligand.

and RHOXF1P1/semaphorin 7A (John Milton Hagen Blood Group)] that may be involved in the pathology of acquired AA (68).

Although there are no studies describing miRNA/lncRNA profiles exclusively in hMDS, there are reports demonstrating that RA and RCMD categories (typical for the majority of hMDS cases) show ncRNA expression patterns distinct from those of other MDS subtypes. Moreover, levels of specific ncRNAs have been successfully used for classification and stratification of patients with $\operatorname{MDS}(42,43,60)$. It may be assumed that hMDS is also associated with specific ncRNA profiles that differ from those of AA and could be used for differentiation. The dysregulation of ncRNAs detected in T cells derived from patients with AA and hMDS indicates that these regulators may contribute to the immunopathogenesis of these disorders.

\section{Pathophysiology}

$M D S$. The overlap of immunological features and the responsiveness of a significant proportion of patients with hMDS/AA to IST suggest that these distinctive clinical entities share an immune-mediated pathogenic mechanism. Clinical and experimental studies have provided compelling evidence that HSPCs are damaged by abnormally activated cytotoxic $\mathrm{T}$ cells (Fig. 2). Expanded $\mathrm{CD}^{+}$and $\mathrm{CD}^{+} \mathrm{T}$ cell clones have been observed in the BM of both patients with hMDS and those with AA $(69,70)$. Melenhorst et al (71) analyzed the $\mathrm{CD}^{+}$and $\mathrm{CD}^{+} \mathrm{T}$ cell repertoires in patients with MDS by flow cytometry and PCR. Multiple T cell expansions (of both helper and cytotoxic $\mathrm{T}(\mathrm{Tc})$ cells) were observed, as well as the functional differentiation in vivo of $\mathrm{T}$ cells from memory to effector $\mathrm{T}$ cells, in $\mathrm{CD}^{+}$cells. Similar findings were reported by Fozza et al (72), supporting the involvement of cytotoxic $\mathrm{T}$ cells either in antitumor immune surveillance or in autoreactive aggression toward hematopoietic precursors. Moreover, dominant $\mathrm{T}$ cell clones persist in patients with MDS that is unresponsive to immunosuppression and regress in responders (73). Strong polarization of $\mathrm{BM} \mathrm{CD} 4^{+}$cells toward Th1 and of $\mathrm{CD}^{+}$cells toward Tc1 was observed in low-risk MDS compared with that in AA, suggesting T cell stimulation from clones of malignant hematopoietic cells (74). Regulatory $\mathrm{T}$ cells (Tregs) are deficient in quantity and function in patients with early MDS (75). The function of Tregs is to suppress the autoreactivity of other $\mathrm{T}$ cell populations to normal tissue; thus, their hypofunction may favour the autoimmune destruction of HSPCs (76).

The antigens that trigger the immune response in MDS are not known, but potential candidates [such as Wilms tumor protein 1 (WT1)] have been suggested. As patients with MDS and trisomy 8 often show a good response to IST, an immunological mechanism underlying BMF has been proposed. Trisomy 8 cells express high levels of $W T 1$, and $\mathrm{CD}^{+} \mathrm{T}$ cells are able to recognize WT1 peptides and induce IFN- $\gamma$ expression in vitro, suggesting that this antigen may contribute to the induction of an immune response (77). Sloand et al (78) further demonstrated that marrow HSCs with trisomy 8 may escape $\mathrm{T}$ cell-mediated destruction by overexpression of prosurvival protein cyclin D1 and survivin. Other neoantigens or overexpressed self-antigens [human leukocyte antigen (HLA)-A2-restricted nonameric peptide] may also elicit an immune response (79). 
Abnormal overproduction of proinflammatory cytokines [such as TNF- $\alpha$, IFN- $\gamma$ and interleukin 17 (IL-17)] has been reported in patients with MDS and contributes also to ineffective hematopoiesis $(80,81)$. In patients with low-risk MDS, the G/A polymorphism in the $T N F-\alpha$ promoter is associated with high levels of TNF- $\alpha$ produced by $\mathrm{CD}^{+}$and $\mathrm{CD}^{+} \mathrm{T}$ lymphocytes (82), suggesting its role in anemia. In a previous study, an increased frequency of $\mathrm{CD}^{+} \mathrm{T}$ cells producing IFN- $\gamma$ was detected in hMDS, and in vitro decrease of interferon by cyclosporine led to improved hematopoiesis (10). The production of IFN- $\gamma$ and TNF- $\alpha$ in low-risk MDS may be further enhanced by high levels of IL-17 (83). Based on the clinical/immunological/molecular features, Fattizzo et al (84) recently defined two hMDS phenotypes, namely, AA-like and MDS-like hMDS. The first is characterized by prevailing inflammation and immune activation, and a response to IST, and the second is characterized by genetic lesions, clonal selection and an increased risk of leukemic evolution.

$A A$. Up to $80 \%$ of patients with AA show a response to $\mathrm{T}$ cell-directed IST, supporting involvement of aberrant $\mathrm{T}$ cell populations in the pathogenesis. As in hMDS, BM T cells are also skewed toward oligo/polyclonal patterns in acquired AA $(16,70,85)$. Giudice et al (85) observed oligoclonal characteristics in $\mathrm{CD}^{+} \mathrm{CD} 57^{+}$cells, as well as in total $\mathrm{CD}^{+} \mathrm{T}$ cells from patients with AA. de Latour et al (86) found an increased population of $\mathrm{CD}^{+} \mathrm{CD} 4{ }^{+} \mathrm{IL}-17$-producing $\mathrm{T}$ cells in patients with AA at presentation compared with that in controls, and this correlated with disease activity. Abnormally activated T cells destroy HSPCs through apoptosis [via Fas cell surface death receptor (Fas)/Fas ligand, granzyme, perforin] and the overproduction of proinflammatory cytokines. Extensive apoptosis of BM HSPCs has been observed in patients with AA, indicating that apoptosis is a major mechanism of cell destruction (87). BM CD $34^{+}$progenitor cells and lymphocytes of patients with AA overexpress Fas, which is involved in triggering the Fas-mediated apoptotic pathway (88). By contrast, normal expression of Fas has been observed in patients with AA in remission (89). Overproduction of cytokines may upregulate the expression of Fas (77).

As in hMDS, AA Tregs exhibit a decreased quantity and ability to suppress the proliferation of autologous T cells. Deep phenotyping of AA Tregs defined two specific Treg subpopulations, Treg A and Treg B, that may predict the response to IST. The Treg B subpopulation with a memory/activated phenotype was overrepresented in IST responders, while the Treg A subpopulation was significantly higher in non-responders. Furthermore, Tregs from patients with AA were IL-2-sensitive and could be expanded in vitro (90).

AA is strongly associated with PNH. PNH clones deficient in glycosyl-phosphatidylinositol (GPI)-anchored proteins appear to be spared by the immune attack mediated by $\mathrm{T}$ cells in BMF syndromes. PNH clones are frequently found in acquired AA $(\leq 60 \%)$ and are also observed in MDS $(10-20 \%$, more common in low-risk cases) (91). The mechanism of this escape is not clear. It has been suggested that antigen targets of $\mathrm{T}$ cell attack or coregulators are GPI-linked proteins. Gargiulo et al (92) demonstrated that CD1d-restricted, GPI-specific $\mathrm{CD}^{+} \mathrm{T}$ cells are expanded in patients with $\mathrm{PNH}$, suggesting that the GPI may be targeted by autoreactive T cells and that these $\mathrm{T}$ cell clones are responsible for the BMF in PNH. Hanaoka et al (93) suggested that immunoselection of PIGA mutant cells is due to a deficiency in the stress-inducible GPI-linked membrane proteins UL16 binding protein 1 and 2, which activate natural killer and T cells. Furthermore, PIGA clones may acquire additional somatic mutations (TET2, SUZ12 polycomb repressive complex 2 subunit, $U 2 A F 1$ and $J A K 2$ ), resulting in a proliferative advantage (94). Mechanisms and factors implicated in the immunopathogenesis of AA and hMDS are summarized in Table III.

In addition to the $\mathrm{T}$ cell-mediated immune response, aging, which is associated with numerous changes in the immune system, including chronic low-grade inflammation (known as inflammaging), may be involved in the development of AA and hMDS in elderly patients (95).

\section{Genetic and molecular basis of an aberrant immune re- sponse}

The genetic and molecular basis of an abnormal $\mathrm{T}$ cell response is being studied. Several polymorphisms in cytokine genes (e.g., IFN- $\gamma$, TNF- $\alpha$ and IL-6) have been linked to the high production of proinflammatory cytokines in AA and MDS $(82,96)$. Furthermore, specific HLA haplotypes are associated with the AA phenotype and response to IST, suggesting that cytotoxic $\mathrm{T}$ cells may target the autoantigens presented on HSCs through these HLA class I molecules. HLA-DR15 (a serological split of HLA-DR2) is overrepresented in AA patients and MDS patients with RA compared with that in their healthy counterparts (97). The presence of this HLA allele is associated with a better response to IST in AA (98). Notably, patients with MDS bearing a PNH clone have a significantly higher HLA-DR15 allele frequency (99). Katagiri et al (100) demonstrated frequent loss of HLA alleles associated with copy number-neutral $6 \mathrm{pLOH}$ in acquired AA. Notably, the missing HLA alleles in $6 \mathrm{pLOH}(+)$ clones included HLA-A*02:01, $A^{*}$ 02:06, $A * 31: 01$ and $B * 40: 02$, which were overrepresented in the germline of patients with AA. Osumi et al (101) suggested that $H L A-B * 40: 02$ is one of the target antigens of $\mathrm{T}$ cells in idiopathic AA and that mutations in this HLA allele contribute to clonal escape. Babushok et al (102) screened patients with AA for somatic HLA class 1 loss and detected it in $17 \%$ of cases. Furthermore, the loss was correlated with a more severe disease course and more frequent evolution to MDS. Mutations in $\beta 2$-microglobulin gene may represent another mechanism of MHC class I loss leading to defective CD4- $8^{+}$cell-mediated cytotoxicity (103).

Defective telomere homeostasis is also suggested to play a role in the pathogenesis of AA and MDS. Approximately $35 \%$ of patients with AA show telomere length shortening in peripheral granulocytes and mononuclear cells. Patients with AA responsive to IST do not possess telomeres that differ in length compared with controls, while untreated patients and non-responders show marked telomere shortening (104). The degree of telomere erosion has been correlated with the severity of AA, risk of relapse, overall survival rate and risk of clonal evolution to MDS (105). In MDS, telomere shortening is mostly linked to disease progression and leukemic transformation into AML. A decrease in telomere length was also observed in 


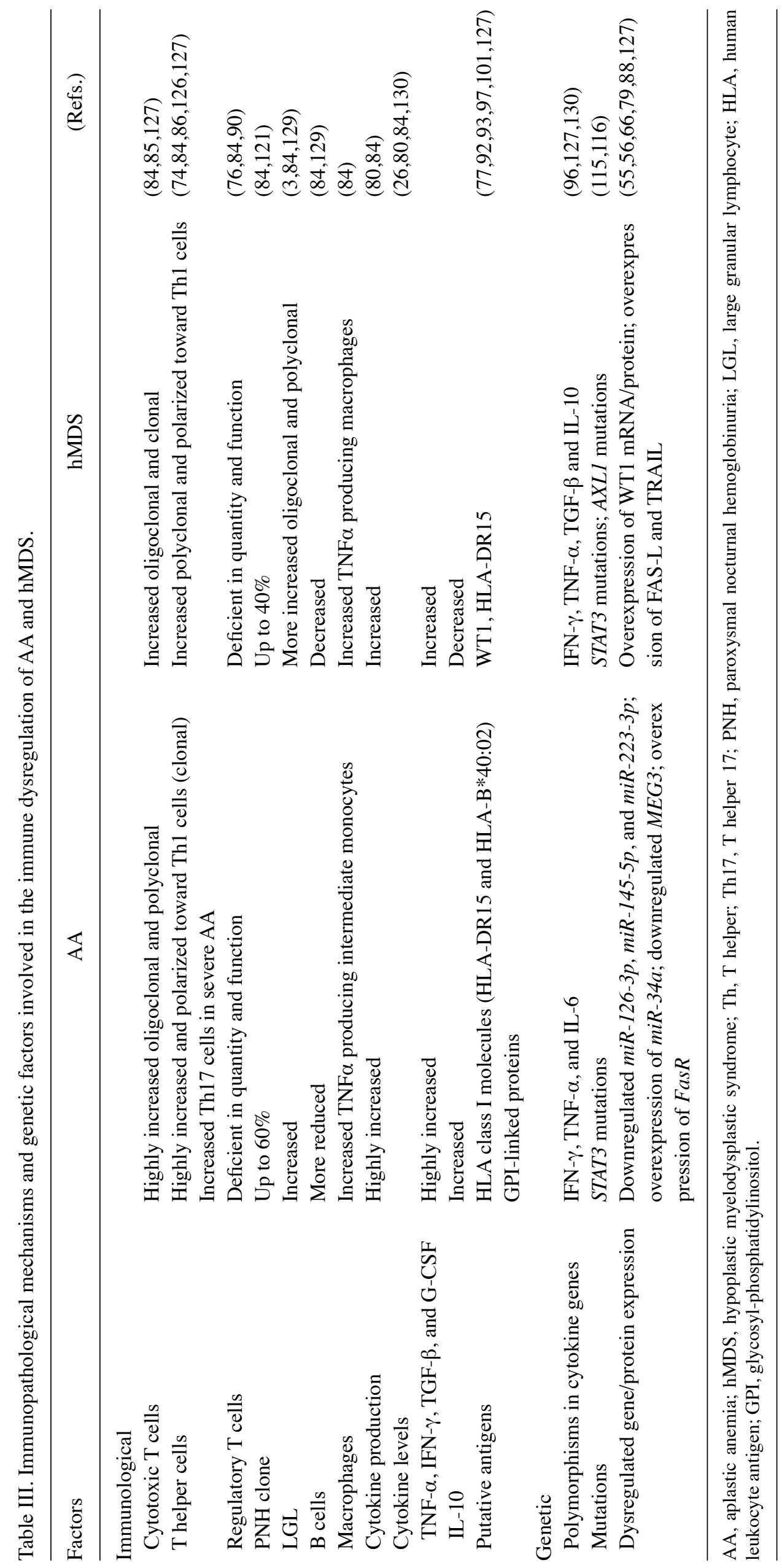


low-risk MDS patients with RA (42\%) and patients with low to intermediate-1 risk (43.1 and 30.8\%, respectively), according to the International Prognostic Scoring System, compared with age-matched controls (106-108). Bouillon et al (109) found significantly shortened age-adapted telomere length in both patients with hMDS and those with AA, but patients with AA showed more accelerated telomere shortening compared with patients with hMDS.

Mutations in telomerase complex genes (telomerase RNA component and telomerase reverse transcriptase) have been reported in AA and MDS $(110,111)$; however, the mutations are considered risk factors for BMF rather than genetic determinants (112). Genetic variants of other telomerase genes, i.e., telomeric repeat binding actor $1 / 2$, may be associated with risk for AA; however, they are rare (113). Furthermore, the presence of pathogenic regulator of telomere elongation helicase 1 variants, resulting in telomere erosion, has been associated with AA and hMDS (114).

In MDS, AXL1 mutation appears to be relevant to immune-mediated BMFF, since patients with this mutation show an upregulation of the immune response pathway compared with patients with wild-type ASXL1 (115). Furthermore, acquired signal transducer and activator of transcription 3 mutations have been found predominantly in acquired AA and MDS with hypoplastic features, suggesting that they may result in self-reactivation of cytotoxic T lymphocytes (116). Notably, some immunodeficiencies, such as cytotoxic $\mathrm{T}$ lymphocyte associated antigen deficiency and deficiency of adenosine deaminase 2 , are associated with iAA (117). GATA2 deficiency is also associated with AA and its clonal evolution to myeloid malignancies (118).

Potential implications of ncRNAs in the immunopathogenesis of BMF were demonstrated the study by Hosokawa et al (55), which detected downregulation of $m i R-126-3 p$ and $m i R-223-3 p$ in $\mathrm{CD}^{+} \mathrm{T}$ effector memory cells and downregulation of $m i R-126-3 p, m i R-145-5 p$ and $m i R-223-3 p$ in $\mathrm{CD}^{+} \mathrm{T}$ effector memory and terminal effector cells in AA. $m i R-126-3 p$ and $m i R-145-5 p$ targeted $M Y C$ and $P I K 3 R 2$, which were upregulated in the $\mathrm{CD} 4^{+}$and $\mathrm{CD} 8^{+} \mathrm{T}$ cells of the patients with AA. Notably, successful IST was associated with the recovery of miRNA levels.

\section{Conclusions}

Although acquired AA and hMDS represent distinct clinical entities, they show considerable clinicopathological similarities and are difficult to distinguish from each other. The overlaps likely originate from a common pathogenic mechanism based on cytotoxic $\mathrm{T}$ cell-mediated attack against certain antigens located on stem or more lineage-restricted progenitor cells. Despite the overlaps, these disorders differ in some characteristics that are an important part of the differential diagnosis. However, the cytological/morphological differences may be subtle due to severe hypocellularity in some cases and need to be evaluated carefully in the context of other findings.

Deep phenotyping has proposed that hMDS is a mixed phenotypic entity comprising of two phenotypes, one resembling AA (non-malignant BMF) and one closer to that of
NH-MDS (BMF prone to malignant transformation). A similar situation likely exists also in AA, in which a small proportion of patients transform to MDS and/or AML, even after successful IST in some cases. Identifying patients at risk of disease progression is a crucial step for early intervention and appropriate follow-up.

The NGS era has increased our knowledge of genetic lesions in these disorders and improved the diagnostic specificity of identifying malignant myelodysplasia; however, there are no specific mutations that clearly separate AA from hMDS. Mutations in BCOR/BCORL1, PIGA, DNMT3A and $A S X L 1$ genes are prevalent in AA, but DNMT3A and ASXL1 mutations are also found in MDS. Clones with DNMT3A and ASXL1 mutations usually increase in size and predict a poorer response to IST and progression to MDS/AML. By contrast, BCOR, BCORL1 and PIGA-mutated clones remain small or disappear and predict a better response to IST and favourable outcomes of AA. High diversity of mutational profiles, driver vs. passenger mutations and infrequently mutated genes of unclear pathogenetic relevance are challenging aspects of NGS testing. The role of other molecular factors in BMF, such as ncRNAs, is also being explored. With the development of RNA interference technology and miRNA-inhibitory agents, these RNAs may provide novel therapeutic approaches in autoimmune disorders.

In conclusion, the diagnostic criteria defining boundaries between AA and hMDS remain the focus of debate and will surely be refined by the incorporation of molecular features into classification schemes.

\section{Acknowledgements}

Not applicable.

\section{Funding}

This study was supported by Ministry of Health of the Czech Republic (grant no. NU21-03-00565).

\section{Availability of data and materials}

Not applicable.

\section{Authors' contributions}

HV wrote the manuscript. MB critically revised the manuscript. All authors read and approved the final manuscript. Data authentication is not applicable.

\section{Ethics approval and consent to participate}

Not applicable.

\section{Patient consent for publication}

Not applicable.

\section{Competing interests}

The authors declare that they have no competing interests. 


\section{References}

1. Germing U, Aul C, Niemeyer CM, Haas R and Bennett JM: Epidemiology, classification and prognosis of adults and children with myelodysplastic syndromes. Ann Hematol 87: 691-699, 2008

2. Germing U, Strupp C, Kündgen A, Bowen D, Aul C, Haas R and Gattermann N: No increase in age-specific incidence of myelodysplastic syndromes. Haematologica 89: 905-910, 2004.

3. Durrani J and Maciejewski JP: Idiopathic aplastic anemia vs hypocellular myelodysplastic syndrome. Hematology Am Soc Hematol Educ Program 2019: 97-104, 2019.

4. Arber DA, Orazi A, Hasserjian R, Thiele J, Borowitz MJ, Le Beau MM, Bloomfield CD, Cazzola M and Vardiman JW: The 2016 revision to the World Health Organization classification of myeloid neoplasms and acute leukemia. Blood 127: 2391-2405, 2016

5. Bono E, McLornan D, Travaglino E, Gandhi S, Gallì A, Khan AA, Kulasekararaj AG, Boveri E, Raj K, Elena C, et al: Clinical, histopathological and molecular characterization of hypoplastic myelodysplastic syndrome. Leukemia 33: 2495-2505, 2019.

6. Huang TC, Ko BS, Tang JL, Hsu C, Chen CY, Tsay W, Huang SY, Yao M, Chen YC, Shen MC, et al: Comparison of hypoplastic myelodysplastic syndrome (MDS) with normo-/hypercellular MDS by International prognostic scoring system, cytogenetic and genetic studies. Leukemia 22: 544-550, 2008

7. Marisavljevic D, Cemerikic V, Rolovic Z, Boskovic D and Colovic M: Hypocellular myelodysplastic syndromes: Clinical and biological significance. Med Oncol 22: 169-175, 2005.

8. Yue G, Hao S, Fadare O, Baker S, Pozdnyakova O, Galili N, Woda BA, Raza A and Wang SA: Hypocellularity in myelodysplastic syndrome is an independent factor which predicts a favorable outcome. Leuk Res 32: 553-558, 2008.

9. Stahl M, DeVeaux M, de Witte T, Neukirchen J, Sekeres MA, Brunner AM, Roboz GJ, Steensma DP, Bhatt VR, Platzbecker U, et al: The use of immunosuppressive therapy in MDS: Clinical outcomes and their predictors in a large international patient cohort. Blood Adv 2: 1765-1772, 2018.

10. Selleri C, Maciejewski JP, Catalano L, Ricci P, Andretta C, Luciano L and Rotoli B: Effects of cyclosporine on hematopoietic and immune functions in patients with hypoplastic myelodysplasia: In vitro and in vivo studies. Cancer 95: 1911-1922, 2002.

11. Gil-Perez A and Montalban-Bravo G: Management of myelodysplastic syndromes after failure of response to hypomethylating agents. Ther Adv Hematol 10: 2040620719847059, 2019.

12. Nazha A, Narkhede M, Radivoyevitch T, Seastone DJ, Patel BJ, Gerds AT, Mukherjee S, Kalaycio M, Advani A, Przychodzen B, et al: Incorporation of molecular data into the revised international prognostic scoring system in treated patients with myelodysplastic syndromes. Leukemia 30: 2214-2220, 2016

13. Bond DR, Lee HJ and Enjeti AK: Unravelling the epigenome of myelodysplastic syndrome: Diagnosis, prognosis, and response to therapy. Cancers (Basel) 12: 3128, 2020

14. Zhou M, Wu L, Zhang Y, Mo W, Li Y, Chen X, Wang C, Pan S, $\mathrm{Xu} \mathrm{S}$, Zhou W, et al: Outcome of allogeneic hematopoietic stem cell transplantation for hypoplastic myelodysplastic syndrome. Int J Hematol 112: 825-834, 2020.

15. Issaragrisil S, Kaufman DW, Anderson T, Chansung K, Leaverton PE, Shapiro S and Young NS: The epidemiology of aplastic anemia in Thailand. Blood 107: 1299-1307, 2006.

16. Shallis RM, Ahmad R and Zeidan AM: Aplastic anemia: Etiology, molecular pathogenesis, and emerging concepts. Eur J Haematol 101: 711-720, 2018.

17. Alter BP: Diagnosis, genetics, and management of inherited bone marrow failure syndromes. Hematology Am Soc Hematol Educ Program 2007: 29-39, 2007.

18. Young NS: Aplastic anemia. N Engl J Med 379: 1643-1656, 2018

19. Afable MG II, Tiu RV and Maciejewski JP: Clonal evolution in aplastic anemia. Hematology Am Soc Hematol Educ Program 2011: 90-95, 2011

20. Risitano AM: Immunosuppressive therapies in the management of acquired immune-mediated marrow failures. Curr Opin Hematol 19: 3-13, 2012.

21. Koh Y, Lee HR, Kim HK, Kim I, Park S, Park MH, Kim BK, Yoon SS and Lee DS: Hypoplastic myelodysplastic syndrome (h-MDS) is a distinctive clinical entity with poorer prognosis and frequent karyotypic and FISH abnormalities compared to aplastic anemia (AA). Leuk Res 34: 1344-1350, 2010.

22. Fattizzo B, Dunlop A, Ireland R, Kassam S, Yallop D, Mufti G, Marsh J and Kulasekararaj A: Prevalence of small PNH clones and their prognostic significance in patients tested for unusual indications: A single center experience. Br J Haematol 185: 125, 2019.
23. Kulasekararaj AG, Jiang J, Smith AE, Mohamedali AM, Mian S, Gandhi S, Gaken J, Czepulkowski B, Marsh JC and Mufti GJ: Somatic mutations identify a subgroup of aplastic anemia patients who progress to myelodysplastic syndrome. Blood 124: 2698-2704, 2014.

24. Zhu Y, Gao Q, Hu J, Liu X, Guan D and Zhang F: Allo-HSCT compared with immunosuppressive therapy for acquired aplastic anemia: A system review and meta-analysis. BMC Immunol 21: 10, 2020.

25. Bennett JM and Orazi A: Diagnostic criteria to distinguish hypocellular acute myeloid leukemia from hypocellular myelodysplastic syndromes and aplastic anemia: Recommendations for a standardized approach. Haematologica 94: 264-268, 2009.

26. Feng X, Scheinberg P, Wu CO, Samsel L, Nunez O, Prince C, Ganetzky RD, McCoy JP Jr, Maciejewski JP and Young NS: Cytokine signature profiles in acquired aplastic anemia and myelodysplastic syndromes. Haematologica 96: 602-606, 2011.

27. Warlick ED and Smith BD: Myelodysplastic syndromes: Review of pathophysiology and current novel treatment approaches. Curr Cancer Drug Targets 7: 541-558, 2007.

28. Ganguly BB and Kadam NN: Mutations of myelodysplastic syndromes (MDS): An update. Mutat Res Rev Mutat Res 769: 47-62, 2016.

29. Nazha A, Seastone D, Radivoyevitch T, Przychodzen B, Carraway HE, Patel BJ, Carew J, Makishima H, Sekeres MA and Maciejewski JP: Genomic patterns associated with hypoplastic compared to hyperplastic myelodysplastic syndromes. Haematologica 100: e434-e437, 2015.

30. Yao CY, Hou HA, Lin TY, Lin CC, Chou WC, Tseng MH, Chiang YC, Liu MC, Liu CW, Kuo YY, et al: Distinct mutation profile and prognostic relevance in patients with hypoplastic myelodysplastic syndromes (h-MDS). Oncotarget 7: 63177-63188, 2016.

31. Schwartz JR, Ma J, Lamprecht T, Walsh M, Wang S, Bryant V, Song G, Wu G, Easton J, Kesserwan C, et al: The genomic landscape of pediatric myelodysplastic syndromes. Nat Commun 8: 1557, 2017.

32. Mufti GJ and Marsh JCW: Somatic mutations in aplastic anemia. Hematol Oncol Clin North Am 32: 595-607, 2018.

33. Stanley N, Olson TS and Babushok DV: Recent advances in understanding clonal haematopoiesis in aplastic anaemia. Br J Haematol 177: 509-525, 2017

34. Yoshizato T, Dumitriu B, Hosokawa K, Makishima H, Yoshida K, Townsley D, Sato-Otsubo A, Sato Y, Liu D, Suzuki H, et al: Somatic mutations and clonal hematopoiesis in aplastic anemia. N Engl J Med 373: 35-47, 2015

35. Marsh JC and Kulasekararaj AG: Management of the refractory aplastic anemia patient: What are the options? Blood 122:3561-3567, 2013.

36. Keel SB, Scott A, Sanchez-Bonilla M, Ho PA, Gulsuner S, Pritchard CC, Abkowitz JL, King MC, Walsh T and Shimamura A: Genetic features of myelodysplastic syndrome and aplastic anemia in pediatric and young adult patients. Haematologica 101: 1343-1350, 2016

37. Huang J, Ge M, Lu S, Shi J, Li X, Zhang J, Wang M, Yu W, Shao Y, Huang Z, et al: Mutations of ASXL1 and TET2 in aplastic anemia. Haematologica 100: e172-e175, 2015

38. Heuser M, Schlarmann C, Dobbernack V, Panagiota V, Wiehlmann L, Walter C, Beier F, Ziegler P, Yun H, Kade S, et al: Genetic characterization of acquired aplastic anemia by targeted sequencing. Haematologica 99: e165-e167, 2014.

39. Lekka E and Hall J: Noncoding RNAs in disease. FEBS Lett 592 : 2884-2900, 2018

40. Kuang X, Chi J and Wang L: Deregulated microRNA expression and its pathogenetic implications for myelodysplastic syndromes. Hematology 21: 593-602, 2016.

41. Rhyasen GW and StarczynowskiDT: Deregulation of microRNAs in myelodysplastic syndrome. Leukemia 26: 13-22, 2012.

42. Dostalova Merkerova M, Krejcik Z, Votavova H, Belickova M, Vasikova A and Cermak J: Distinctive microRNA expression profiles in $\mathrm{CD} 34+$ bone marrow cells from patients with myelodysplastic syndrome. Eur J Hum Genet 19: 313-319, 2011.

43. Sokol L, Caceres G, Volinia S, Alder H, Nuovo GJ, Liu CG, McGraw K, Clark JA, Sigua CA, Chen DT, et al: Identification of a risk dependent microRNA expression signature in myelodysplastic syndromes. Br J Haematol 153: 24-32, 2011.

44. Boultwood J, Fidler C, Strickson AJ, Watkins F, Gama S Kearney L, Tosi S, Kasprzyk A, Cheng JF, Jaju RJ and Wainscoat JS: Narrowing and genomic annotation of the commonly deleted region of the 5q-syndrome. Blood 99: 4638-4641, 2002.

45. Pidíkova P, Reis R and Herichova I: miRNA clusters with down-regulated expression in human colorectal cancer and their regulation. Int J Mol Sci 21: 4633, 2020. 
46. Takagi T, Iio A, Nakagawa $\mathrm{Y}$, Naoe $\mathrm{T}$, Tanigawa $\mathrm{N}$ and Akao $\mathrm{Y}$ : Decreased expression of microRNA-143 and -145 in human gastric cancers. Oncology 77: 12-21, 2009.

47. Starczynowski DT, Kuchenbauer F, Argiropoulos B, Sung S, Morin R, Muranyi A, Hirst M, Hogge D, Marra M, Wells RA, et al: Identification of miR-145 and miR-146a as mediators of the 5q-syndrome phenotype. Nat Med 16: 49-58, 2010.

48. Votavova H, Grmanova M, Dostalova Merkerova M, Belickova M, Vasikova A, Neuwirtova R and Cermak J: Differential expression of microRNAs in CD34+ cells of 5q-syndrome. J Hematol Oncol 4: 1, 2011.

49. Barreyro L, Chlon TM and Starczynowski DT: Chronic immune response dysregulation in MDS pathogenesis. Blood 132: $1553-1560,2018$

50. Gañán-Gómez I, Wei Y, Yang H, Pierce S, Bueso-Ramos C, Calin G, Boyano-Adánez Mdel C and García-Manero G: Overexpression of miR-125a in myelodysplastic syndrome CD34+ cells modulates NF- $\mathrm{KB}$ activation and enhances erythroid differentiation arrest. PLoS One 9: e93404, 2014.

51. Srivastava J, Chaturvedi CP, Rahman K, Gupta R, Sharma A, Chandra D, Singh MK, Gupta A, Yadav S and Nityanand S: Differential expression of miRNAs and their target genes: Exploring a new perspective of acquired aplastic anemia pathogenesis. Int J Lab Hematol 42: 501-509, 2020.

52. Lu S, Yadav AK and Qiao X: Identification of potential miRNA-mRNA interaction network in bone marrow T cells of acquired aplastic anemia. Hematology 25: 168-175, 2020.

53. Adhikari S and Mandal P: Integrated analysis of global gene and microRNA expression profiling associated with aplastic anaemia. Life Sci 228: 47-52, 2019.

54. Hosokawa K, Kajigaya S, Feng X, Desierto MJ, Fernandez Ibanez MD, Rios O, Weinstein B, Scheinberg P, Townsley DM and Young NS: A plasma microRNA signature as a biomarker for acquired aplastic anemia. Haematologica 102: 69-78, 2017.

55. Hosokawa K, Muranski P, Feng X, Keyvanfar K, Townsley DM, Dumitriu B, Chen J, Kajigaya S, Taylor JG, Hourigan CS, et al Identification of novel microRNA signatures linked to acquired aplastic anemia. Haematologica 100: 1534-1545, 2015.

56. Sun YX, Li H, Feng Q, Li X, Yu YY, Zhou LW, Gao Y, Li GS Ren J, Ma CH, et al: Dysregulated miR34a/diacylglycerol kinase $\zeta$ interaction enhances T-cell activation in acquired aplastic anemia. Oncotarget 8: 6142-6154, 2017.

57. Giudice V, Banaszak LG, Gutierrez-Rodrigues F, Kajigaya S, Panjwani R, Ibanez MDPF, Rios O, Bleck CK, Stempinski ES, Raffo DQ, et al: Circulating exosomal microRNAs in acquired aplastic anemia and myelodysplastic syndromes. Haematologica 103: 1150-1159, 2018.

58. Benetatos L, Hatzimichael E, Dasoula A, Dranitsaris G, Tsiara S, Syrrou M, Georgiou I and Bourantas KL: CpG methylation analysis of the MEG3 and SNRPN imprinted genes in acute myeloid leukemia and myelodysplastic syndromes. Leuk Res 34 $148-153,2010$.

59. Szikszai K, Krejcik Z, Klema J, Loudova N, Hrustincova A, Belickova M, Hruba M, Vesela J, Stranecky V, Kundrat D, et al: LncRNA profiling reveals that the deregulation of H19, WT1-AS, TCL6, and LEF1-AS1 is associated with higher-risk myelodysplastic syndrome. Cancers (Basel) 12: 2726, 2020.

60. Yao CY, Chen CH, Huang HH, Hou HA, Lin CC, Tseng MH, Kao CJ, Lu TP, Chou WC and Tien HF: A 4-lncRNA scoring system for prognostication of adult myelodysplastic syndromes. Blood Adv 1: 1505-1516, 2017.

61. Liu K, Beck D, Thoms JAI, Liu L, Zhao W, Pimanda JE and Zhou X: Annotating function to differentially expressed LincRNAs in myelodysplastic syndrome using a network-based method. Bioinformatics 33: 2622-2630, 2017.

62. Wu Z, Gao S, Zhao X, Chen J, Keyvanfar K, Feng X, Kajigaya S and Young NS: Long noncoding RNAs of single hematopoietic stem and progenitor cells in healthy and dysplastic human bone marrow. Haematologica 104: 894-906, 2019.

63. Hung SY, Lin CC, Hsu CL, Yao CY, Wang YH, Tsai CH, Hou HA, Chou WC and Tien HF: The expression levels of long non-coding RNA KIAA0125 are associated with distinct clinical and biological features in myelodysplastic syndromes. $\mathrm{Br} \mathrm{J}$ Haematol 192: 589-598, 2021.

64. Li N, Ma Y, Wang W, Yin CC, Wu W, Sun R, Zhao G, Li S and Wang X: LOC101928834, a novel lncRNA in Wnt/ $\beta$-catenin signaling pathway, promotes cell proliferation and predicts poor clinical outcome in myelodysplastic syndromes. Clin Sci (Lond) 134: 1279-1293, 2020.
65. Congrains-Castillo A, Niemann FS, Santos Duarte AS and Olalla-Saad ST: LEF1-AS1, long non-coding RNA, inhibits proliferation in myeloid malignancy. J Cell Mol Med 23: 3021-3025, 2019

66. Wang J, Liu X, Hao C, Lu Y, Duan X, Liang R, Gao G and Zhang T: MEG3 modulates TIGIT expression and CD4 $+\mathrm{T}$ cell activation through absorbing miR-23a. Mol Cell Biochem 454: 67-76, 2019.

67. Jiang S, Xia M, Yang J, Shao J, Liao X, Zhu J and Jiang H: Novel insights into a treatment for aplastic anemia based on the advanced proliferation of bone marrow-derived mesenchymal stem cells induced by fibroblast growth factor 1 . Mol Med Rep 12: 7877-7882, 2015.

68. Lu S, Song X, Chen J and Qiao X: Identification of differentially expressed lncRNAs and mRNAs in children with acquired aplastic anemia by RNA sequencing. Biomed Res Int 2020: 8962090, 2020.

69. Risitano AM, Maciejewski JP, Green S, Plasilova M, Zeng W and Young NS: In-vivo dominant immune responses in aplastic anaemia: Molecular tracking of putatively pathogenetic T-cell clones by TCR beta-CDR3 sequencing. Lancet 364: 355-364, 2004

70. Risitano AM, Kook H, Zeng W, Chen G, Young NS and Maciejewski JP: Oligoclonal and polyclonal CD4 and CD8 lymphocytes in aplastic anemia and paroxysmal nocturnal hemoglobinuria measured by $\mathrm{V}$ beta CDR3 spectratyping and flow cytometry. Blood 100: 178-183, 2002.

71. Melenhorst JJ, Eniafe R, Follmann D, Nakamura R, Kirby M and Barrett AJ: Molecular and flow cytometric characterization of the CD4 and CD8 T-cell repertoire in patients with myelodysplastic syndrome. Br J Haematol 119: 97-105, 2002.

72. Fozza C, Contini S, Galleu A, Simula MP, Virdis P, Bonfigli S and Longinotti M: Patients with myelodysplastic syndromes display several T-cell expansions, which are mostly polyclonal in the CD4(+) subset and oligoclonal in the CD8(+) subset. Exp Hematol 37: 947-955, 2009.

73. Kochenderfer JN, Kobayashi S, Wieder ED, Su C and Molldrem JJ: Loss of T-lymphocyte clonal dominance in patients with myelodysplastic syndrome responsive to immunosuppression. Blood 100: 3639-3645, 2002.

74. Li X, Xu F, He Q, Wu L, Zhang Z and Chang C: Comparison of immunological abnormalities of lymphocytes in bone marrow in myelodysplastic syndrome (MDS) and aplastic anemia (AA). Intern Med 49: 1349-1355, 2010.

75. Solomou EE, Rezvani K, Mielke S, Malide D, Keyvanfar K, Visconte V, Kajigaya S, Barrett AJ and Young NS: Deficient CD4+ CD25+ FOXP3 + T regulatory cells in acquired aplastic anemia. Blood 110: 1603-1606, 2007.

76. Bouchliou I, Miltiades P, Nakou E, Spanoudakis E, Goutzouvelidis A, Vakalopoulou S, Garypidou V, Kotoula V, Bourikas G, Tsatalas C and Kotsianidis I: Th17 and Foxp3(+) T regulatory cell dynamics and distribution in myelodysplastic syndromes. Clin Immunol 139: 350-359, 2011.

77. Sloand EM and Barrett AJ: Immunosuppression for myelodysplastic syndrome: How bench to bedside to bench research led to success. Hematol Oncol Clin North Am 24: 331-341, 2010.

78. Sloand EM, Mainwaring L, Fuhrer M, Ramkissoon S, Risitano AM, Keyvanafar K, Lu J, Basu A, Barrett AJ and Young NS: Preferential suppression of trisomy 8 compared with normal hematopoietic cell growth by autologous lymphocytes in patients with trisomy 8 myelodysplastic syndrome. Blood 106: 841-851, 2005.

79. Sloand EM, Melenhorst JJ, Tucker ZC, Pfannes L, Brenchley JM, Yong A, Visconte V, Wu C, Gostick E, Scheinberg P, et al: T-cell immune responses to Wilms tumor 1 protein in myelodysplasia responsive to immunosuppressive therapy. Blood 117: 2691-2699, 2011.

80. Kitagawa M, Saito I, Kuwata T, Yoshida S, Yamaguchi S, Takahashi M, Tanizawa T, Kamiyama R and Hirokawa K: Overexpression of tumor necrosis factor (TNF)-alpha and interferon (IFN)-gamma by bone marrow cells from patients with myelodysplastic syndromes. Leukemia 11: 2049-2054, 1997.

81. Allampallam K, Shetty VT and Raza A: Cytokines and MDS Cancer Treat Res 108: 93-100, 2001.

82. StifterG,Heiss S, GastlG,Tzankov A and StauderR:Over-expression of tumor necrosis factor-alpha in bone marrow biopsies from patients with myelodysplastic syndromes: Relationship to anemia and prognosis. Eur J Haematol 75: 485-491, 2005.

83. Zhang Z, Li X, Guo J, Xu F, He Q, Zhao Y, Yang Y, Gu S, Zhang Y, Wu L and Chang C: Interleukin-17 enhances the production of interferon- $\gamma$ and tumour necrosis factor- $\alpha$ by bone marrow $\mathrm{T}$ lymphocytes from patients with lower risk myelodysplastic syndromes. Eur J Haematol 90: 375-384, 2013. 
84. Fattizzo B, Serpenti F, Barcellini W and Caprioli C: Hypoplastic myelodysplastic syndromes: Just an overlap syndrome? Cancers (Basel) 13: 132, 2021

85. Giudice V, Feng X, Lin Z, Hu W, Zhang F, Qiao W, Ibanez MDPF, Rios O and Young NS: Deep sequencing and flow cytometric characterization of expanded effector memory $\mathrm{CD} 8^{+} \mathrm{CD} 57^{+} \mathrm{T}$ cells frequently reveals T-cell receptor $\mathrm{V} \beta$ oligoclonality and CDR3 homology in acquired aplastic anemia. Haematologica 103: 759-769, 2018.

86. de Latour RP, Visconte V, Takaku T, Wu C, Erie AJ, Sarcon AK, Desierto MJ, Scheinberg P, Keyvanfar K, Nunez O, et al: Th17 immune responses contribute to the pathophysiology of aplastic anemia. Blood 116: 4175-4184, 2010.

87. Vibhuti, Tripathy NK and Nityanand S: Massive apoptosis of bone marrow cells in aplastic anaemia. Br J Haematol 117: 993-994, 2002.

88. Callera F and Falcão RP: Increased apoptotic cells in bone marrow biopsies from patients with aplastic anaemia. Br J Haematol 98: 18-20, 1997.

89. Callera F, Garcia AB and Falcão RP: Fas-mediated apoptosis with normal expression of bcl-2 and p53 in lymphocytes from aplastic anaemia. Br J Haematol 100: 698-703, 1998.

90. Kordasti S, Costantini B, Seidl T, Perez Abellan P, MartinezLlordella M,McLornanD,Diggins KE,Kulasekararaj A, Benfatto C, Feng X, et al: Deep phenotyping of Tregs identifies an immune signature for idiopathic aplastic anemia and predicts response to treatment. Blood 128: 1193-1205, 2016.

91. Young NS and Maciejewski JP: Genetic and environmental effects in paroxysmal nocturnal hemoglobinuria: This little PIG-A goes 'Why? Why? Why?' J Clin Invest 106: 637-641, 2000.

92. Gargiulo L, Papaioannou M, Sica M, Talini G, Chaidos A, Richichi B, Nikolaev AV, Nativi C, Layton M, de la Fuente J, et al: Glycosylphosphatidylinositol-specific CD1d-restricted $\mathrm{T}$ cells in paroxysmal nocturnal hemoglobinuria. Blood 121: 2753-2761, 2013.

93. Hanaoka N, Kawaguchi T, Horikawa K, Nagakura S, Mitsuya $H$ and Nakakuma H: Immunoselection by natural killer cells of PIGA mutant cells missing stress-inducible ULBP. Blood 107: 1184-1191, 2006

94. Shen W, Clemente MJ, Hosono N, Yoshida K, Przychodzen B, Yoshizato T, Shiraishi Y, Miyano S, Ogawa S, Maciejewski JP and Makishima $\mathrm{H}$ : Deep sequencing reveals stepwise mutation acquisition in paroxysmal nocturnal hemoglobinuria. J Clin Invest 124: 4529-4538, 2014

95. Sadighi Akha AA: Aging and the immune system: An overview. J Immunol Methods 463: 21-26, 2018.

96. Gidvani V, Ramkissoon S, Sloand EM and Young NS: Cytokine gene polymorphisms in acquired bone marrow failure. Am J Hematol 82: 721-724, 2007.

97. Saunthararajah Y, Nakamura R, Nam JM, Robyn J, Loberiza F Maciejewski JP, Simonis T, Molldrem J, Young NS and Barrett AJ: HLA-DR15 (DR2) is overrepresented in myelodysplastic syndrome and aplastic anemia and predicts a response to immunosuppression in myelodysplastic syndrome. Blood 100 : $1570-1574,2002$

98. Maciejewski JP, Follmann D, Nakamura R, Saunthararajah Y, Rivera CE, Simonis T, Brown KE, Barrett JA and Young NS: Increased frequency of HLA-DR2 in patients with paroxysmal nocturnal hemoglobinuria and the $\mathrm{PNH} /$ aplastic anemia syndrome. Blood 98: 3513-3519, 2001.

99. Wang H, Chuhjo T, Yasue S, Omine M and Nakao S: Clinical significance of a minor population of paroxysmal nocturnal hemoglobinuria-type cells in bone marrow failure syndrome. Blood 100: 3897-3902, 2002.

100. Katagiri T, Sato-Otsubo A, Kashiwase K, Morishima S, Sato Y Mori Y, Kato M, Sanada M, Morishima Y, Hosokawa K, et al Frequent loss of HLA alleles associated with copy number-neutral $6 \mathrm{pLOH}$ in acquired aplastic anemia. Blood 118 : 6601-6609, 2011

101. Osumi T, Miharu M, Saji H, Kusunoki Y, Kojima H, Nakamura J and Shimada H: Nonsense mutation in HLA-B*40:02 in a case with acquired aplastic anaemia: A possible origin of clonal escape from autoimmune insult. Br J Haematol 162: 706-707, 2013.

102. Babushok DV, Duke JL, Xie HM, Stanley N, Atienza J, Perdigones N, Nicholas P, Ferriola D, Li Y, Huang H, et al Somatic HLA mutations expose the role of class I-mediated autoimmunity in aplastic anemia and its clonal complications. Blood Adv 1: 1900-1910, 2017.
103. Zijlstra M, Bix M, Simister NE, Loring JM, Raulet DH and Jaenisch R: Beta 2-microglobulin deficient mice lack CD4-8+ cytolytic T cells. Nature 344: 742-746, 1990.

104. Brümmendorf TH, Maciejewski JP, Mak J, Young NS and Lansdorp PM: Telomere length in leukocyte subpopulations of patients with aplastic anemia. Blood 97: 895-900, 2001

105. Scheinberg P, Cooper JN, Sloand EM, Wu CO, Calado RT and Young NS: Association of telomere length of peripheral blood leukocytes with hematopoietic relapse, malignant transformation, and survival in severe aplastic anemia. JAMA 304 : 1358-1364, 2010.

106. Boultwood J, Fidler C, Kusec R, Rack K, Elliott PJ, Atoyebi O, Chapman R, Oscier DG and Wainscoat JS: Telomere length in myelodysplastic syndromes. Am J Hematol 56: 266-271, 1997.

107. Rollis on DE, Epling-Burnette PK, Park JY, Lee JH Park H, Jonathan K, Cole AL, Painter JS, Guerrier M, Meléndez-Santiago J, et al: Telomere length in myelodysplastic syndromes. Leuk Lymphoma 52: 1528-1536, 2011.

108. Sanz GF, Sanz MA and Greenberg PL: Prognostic factors and scoring systems in myelodysplastic syndromes. Haematologica 83 358-368, 1998.

109. Bouillon AS, Ferreira MS, Werner B, Hummel S, Panse JP, Reinecke P, Schemenau J, Haas R, Traulsen A, Bruemmendorf TH, et al: Comprehensive analysis of telomere biology in patients with aplastic anemia and hypoplastic myelodysplastic syndrome: Further evidence for a common mechanism. Blood 126: 2858, 2015.

110. Yamaguchi H, Calado RT, Ly H, Kajigaya S, Baerlocher GM, Chanock SJ, Lansdorp PM and Young NS: Mutations in TERT, the gene for telomerase reverse transcriptase, in aplastic anemia. N Engl J Med 352: 1413-1424, 2005.

111. Ueda Y, Calado RT, Norberg A, Kajigaya S, Roos G, HellstromLindberg E and Young NS: A mutation in the H/ACA box of telomerase RNA component gene (TERC) in a young patient with myelodysplastic syndrome. BMC Med Genet 15: 68, 2014.

112. Young NS: Current concepts in the pathophysiology and treatment of aplastic anemia. Hematology Am Soc Hematol Educ Program 2013: 76-81, 2013.

113. Savage SA, Calado RT, Xin ZT, Ly H, Young NS and Chanock SJ: Genetic variation in telomeric repeat binding factors 1 and 2 in aplastic anemia. Exp Hematol 34: 664-671, 2006.

114. Marsh JCW, Gutierrez-Rodrigues F, Cooper J, Jiang J, Gandhi S, Kajigaya S, Feng X, Ibanez MDPF, Donaires FS, Lopes da Silva JP, et al: Heterozygous RTEL1 variants in bone marrow failure and myeloid neoplasms. Blood Adv 2: 36-48, 2018.

115. Thol F, Friesen I, Damm F, Yun H, Weissinger EM, Krauter J, Wagner K, Chaturvedi A, Sharma A, Wichmann M, et al: Prognostic significance of ASXL1 mutations in patients with myelodysplastic syndromes. J Clin Oncol 29: 2499-2506, 2011.

116. Jerez A, Clemente MJ, Makishima H, Rajala H, Gómez-Seguí I, Olson T, McGraw K, Przychodzen B, Kulasekararaj A, Afable M, et al: STAT3 mutations indicate the presence of subclinical T-cell clones in a subset of aplastic anemia and myelodysplastic syndrome patients. Blood 122: 2453-2459, 2013.

117. Kuehn HS, Ouyang W, Lo B, Deenick EK, Niemela JE, Avery DT, Schickel JN, Tran DQ, Stoddard J, Zhang Y, et al: Immune dysregulation in human subjects with heterozygous germline mutations in CTLA4. Science 345: 1623-1627, 2014.

118. Wlodarski MW, Collin M and Horwitz MS: GATA2 deficiency and related myeloid neoplasms. Semin Hematol 54: 81-86, 2017.

119. Ogawa S: Clonal hematopoiesis in acquired aplastic anemia. Blood 128: 337-347, 2016.

120. West RR, Stafford DA, White AD, Bowen DT and Padua RA: Cytogenetic abnormalities in the myelodysplastic syndromes and occupational or environmental exposure. Blood 95: 2093-2097, 2000

121. Negoro E, Nagata Y, Clemente MJ, Hosono N, Shen W, Nazha A, Yoshizato T, Hirsch C, Przychodzen B, Mahfouz RZ, et al: Origins of myelodysplastic syndromes after aplastic anemia. Blood 130: 1953-1957, 2017.

122. Pons A, Nomdedeu B, Navarro A, Gaya A, Gel B, Diaz T, Valera S, Rozman M, Belkaid M, Montserrat E and Monzo M: Hematopoiesis-related microRNA expression in myelodysplastic syndromes. Leuk Lymphoma 50: 1854-1859, 2009.

123. Krejčík Z, Beličková M, Hruštincová A, Kléma J, Zemanová Z, Michalová K, Čermák J,Jonášová A and Dostálová Merkerová M: Aberrant expression of the microRNA cluster in 14q32 is associated with del(5q) myelodysplastic syndrome and lenalidomide treatment. Cancer Genet 208: 156-161, 2015 
124. Starczynowski DT, Kuchenbauer F, Wegrzyn J, Rouhi A, Petriv O, Hansen CL, Humphries RK and Karsan A: MicroRNA-146a disrupts hematopoietic differentiation and survival. Exp Hematol 39: 167-178.e4, 2011

125. Chen Y, Zhao G, Li N, Luo Z, Wang X and Gu J: Role of 4-aminobutyrate aminotransferase (ABAT) and the lncRNA co-expression network in the development of myelodysplastic syndrome. Oncol Rep 42: 509-520, 2019.

126. Kordasti S, Marsh J, Al-Khan S, Jiang J, Smith A, Mohamedali A, Abellan PP, Veen C, Costantini B, Kulasekararaj AG, et al: Functional characterization of CD4+ T cells in aplastic anemia. Blood 119: 2033-2043, 2012.

127. Serio B, Risitano A, Giudice V, Montuori N and Selleri C: Immunological derangement in hypocellular myelodysplastic syndromes. Transl Med UniSa 8: 31-42, 2014.
128. Kordasti SY, Afzali B, Lim Z, Ingram W, Hayden J, Barber L, Matthews K, Chelliah R, Guinn B, Lombardi G, et al: IL-17-producing CD4(+) T cells, pro-inflammatory cytokines and apoptosis are increased in low risk myelodysplastic syndrome. Br J Haematol 145: 64-72, 2009.

129. Zhang HF, Huang ZD, Wu XR, Li Q and Yu ZF: Comparison of $\mathrm{T}$ lymphocyte subsets in aplastic anemia and hypoplastic myelodysplastic syndromes. Life Sci 189: 71-75, 2017.

130. Serio B, Selleri C and Maciejewski JP: Impact of immunogenetic polymorphisms in bone marrow failure syndromes. Mini Rev Med Chem 11: 544-552, 2011.

This work is licensed under a Creative Commons Attribution-NonCommercial-NoDerivatives 4.0 International (CC BY-NC-ND 4.0) License. 